Published in final edited form as:

Org Lett. 2016 May 20; 18(10): 2331-2334. doi:10.1021/acs.orglett.6b00598.

\title{
Synthesis of Cyclic Guanidines via Silver-Catalyzed Intramolecular Alkene Hydroamination Reactions of $\mathbf{N}$ - Allylguanidines
}

\author{
Zachary J. Garlets ${ }^{\dagger}$, Mattia Silvi ${ }^{\ddagger}$, and John P. Wolfe ${ }^{\dagger}{ }^{\star}$ \\ †Department of Chemistry, University of Michigan, 930 North University Avenue, Ann Arbor, \\ Michigan 48109-1055, United States

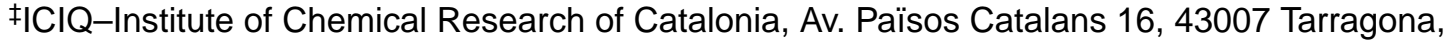 \\ Spain
}

\section{Abstract}

The silver-catalyzed hydroamination of tosyl-protected $N$-allylguanidines is described. These reactions provide substituted cyclic guanidines in high yields. The reactions are amenable to the construction of quaternary stereocenters as well as both monocyclic and bicyclic guanidine products.

\section{Graphical Abstract}

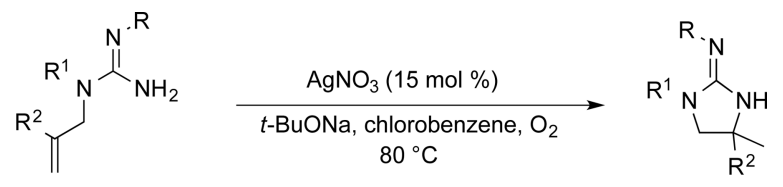

Cyclic guanidines are an important class of compounds that exhibit highly interesting biological activities, and they have also found applications as synthetically useful organocatalysts. The preparation of cyclic guanidines has often been accomplished via ringclosing $\mathrm{S}_{\mathrm{N}} 2$ reactions, haloamination of alkenes, or through guanylation of 1,2-diamine derivatives.' More recent approaches have involved metal-catalyzed transformations that typically allow for generation of cyclic guanidines in an efficient manner from simple precursors.'

One powerful method for the metal-catalyzed synthesis of nitrogen heterocycles that has attracted considerable attention over the past 25 years is the intramolecular hydroamination of amines bearing pendant alkenes. However, despite the high level of activity in this field and the many advances that have resulted, intramolecular alkene hydroamination reactions

\footnotetext{
*Corresponding Author. jpwolfe@umich.edu. ASSOCIATED CONTENT

Supporting Information

Experimental procedures, characterization data for all new compounds, and copies of ${ }^{1} \mathrm{H}$ and ${ }^{13} \mathrm{C}$ NMR spectra for all new compounds. The Supporting Information is available free of charge on the ACS Publications website.

The authors declare no competing financial interest.
} 
of guanidine nucleophiles have not previously been described. Looper, Gin, and van der Eycken have independently conducted elegant work on metal-catalyzed alkyne hydroamination reactions of guanidines, but extension of these methods to analogous alkene hydroaminations has remained elusive.

We recently described a new approach to the synthesis of cyclic guanidines 2 via Pdcatalyzed alkene carboamination reactions between aryl bromides and $N$-allylguanidines bearing $N$-PMP protecting groups (1) (Scheme 1, eq 1)." These transformations provided the desired products in good chemical yield for a variety of different substrate combinations. However, removal of the PMP protecting groups proved to be quite challenging, and efforts to cleave both PMP groups from the product were not successful.

To overcome this limitation, we began to explore alternative $\mathrm{N}$-protecting groups for the carboamination reactions, and initial studies on the use of substrates bearing a single $N$-tosyl protecting groups (e.g., 3a) provided promising preliminary results. During efforts to optimize these reactions we examined the influence of silver salts on reactions of $\mathbf{3 a}$, as other studies conducted in our lab suggested that formation of cationic intermediate palladium complexes may facilitate reactions of relatively electron-poor substrates.' Although these conditions failed to provide the desired alkene carboamination product 4 (Scheme 1, eq 2), we were intrigued to discover that the cyclic guanidine $\mathbf{5 a}$ derived from the hydroamination of the alkene was produced in $20 \%$ yield. A series of control reactions demonstrated that the palladium was not necessary for the transformation to occur, but the presence of silver acetate (1 equiv), and base was required for the reaction to occur.

Given the significance of the guanidine products and the novelty of the hydroamination reaction, we set out to optimize the Ag-catalyzed conversion of $\mathbf{3 a}$ to $\mathbf{5 a}$ (Table 1). Since our preliminary result employed a stoichiometric amount of $\mathrm{AgOAc}$, we began our optimization studies by modifying the conditions shown in Scheme 1, eq 2 by simply omitting the aryl bromide and the palladium catalyst, and decreasing the loading of silver acetate to $10 \mathrm{~mol} \%$ (Table 1, entry 1). Unfortunately, these conditions failed to produce the desired product. However, use of AgOTf as catalyst and a higher reaction temperature $\left(138^{\circ} \mathrm{C}\right)$ did result in catalyst turnover, and provided the desired product in $40 \%$ yield (Table 1, entry 3 ). Omission of the phosphine ligand from the reaction mixture led to a slight improvement in yield (45\%) (Table 1, entry 4). A brief survey of copper and gold catalysts did not provide satisfactory results.

During the course of these optimization studies we noticed that chemical yields were not satisfactorily reproducible, and we began to suspect that adventitious oxygen may play a role in these reactions. As such, we carried out the AgOTf-catalyzed hydroamination of 3a under an atmosphere of oxygen and were pleased to discover the desired product was formed in $70 \%$ yield (Table 1, entry 9). When silver nitrate was employed as catalyst and the concentration was decreased to $0.033 \mathrm{M}$ the reaction provided $99 \%$ yield of $\mathbf{5 a}$ (Table 1, entry 10). Finally, the use of chlorobenzene as solvent allowed the reactions to be conducted at a higher, more synthetically useful concentration $(0.1 \mathrm{M})$ at lower temperature $\left(80{ }^{\circ} \mathrm{C}\right)$. 
Further experimentation indicated the reaction could be conducted under an atmosphere of air rather than $\mathrm{O}_{2}$ (Table 1, entries 13-14). However, reactions carried out under air proved to give inconsistent results that appeared to depend on the level of atmospheric humidity present on any given day. Control experiments were carried out under a nitrogen atmosphere to further examine the role of $\mathrm{O}_{2}$ in these reactions. Treatment of $\mathbf{3 a}$ with $10 \mathrm{~mol} \% \mathrm{AgNO}_{3}$ under $\mathrm{N}_{2}$ in degassed chlorobenzene led to only $60 \%$ conversion of starting material to product (Table 1, entry 16). However, use of a full equivalent of $\mathrm{AgNO}_{3}$ under these oxygenfree conditions gave results comparable to the use of $10 \mathrm{~mol} \% \mathrm{AgNO}_{3}$ under an oxygen atmosphere (Table 1, entry 17).

Before further exploring the scope of these reactions, we quickly surveyed the influence of two other nitrogen protecting groups on reactivity. As shown in Scheme 2, eq 3, use of substrate $\mathbf{6}$ bearing a $N$-p-methoxyphenylsulfonyl group led to the formation of the desired product 7 in $96 \%$ yield. Unfortunately efforts to prepare the analogous $p$-nitrophenyl derivative have thus far been unsuccessful. In addition, the reaction of di-boc protected substrate $\mathbf{8}$ failed to produce the desired hydroamination product (Scheme 2, eq 4).

In order to examine the scope of the silver-catalyzed guanidine hydroamination reactions, several substrates with different substitution patterns were synthesized and subjected to the optimized reaction conditions. As shown in Table 2, substrates $\mathbf{3 a - 3 d}$ and $\mathbf{3 g}-\mathbf{3 j}$ bearing a variety of substituents on the non-cyclizing nitrogen atom were converted to the desired products in excellent yields (Table 2, entries 1-4 and 7-10). In addition, substitution on the internal alkene carbon was tolerated as substrates $\mathbf{3 e}$ and $\mathbf{3 f}$ were converted to cyclic guanidines $\mathbf{5 e}$ and $\mathbf{5 f}$ in high yield (Table 2, entries 5-6), although slightly higher reaction temperatures $\left(100^{\circ} \mathrm{C}\right)$ were required in these cases. Several functional groups including a cyclic acetal (Table 2, entry 8), an aryl ether (Table 2, entry 10), and a TBS-protected alcohol (Table 2, entry 9) were also tolerated, although approximately $20 \%$ of desilylated product was generated in this latter reaction. Although transformations of 1,1-disubstituted alkene substrates proceeded smoothly, efforts to carry out the Ag-catalyzed hydroamination of 1,2-disubstituted alkene substrates $\mathbf{9}$ or $\mathbf{1 0}$ (Scheme 3, eq 5) were unsuccessful. No desired products were obtained in these reactions even with increased catalyst loadings (40 mol $\% \mathrm{Ag})$ and temperatures $\left(138^{\circ} \mathrm{C}\right)$. In addition, preliminary studies on 6-membered ring formation from substrate $\mathbf{1 1}$ failed to produce the desired cyclic guanidine product.

To explore the diastereoselectivity of these reactions, we sought to prepare substrates analogous to 3 but bearing a substituent (methyl or phenyl) at the allylic position. Unfortunately use of standard methods to generate these compounds has thus far been unsuccessful. Nonetheless, we were gratified to find the intramolecular alkene hydroamination reactions are amenable to the stereoselective construction of bicyclic guanidine derivatives. As shown in Scheme 4, eq 6, treatment of 12 with a $\mathrm{AgNO}_{3}$ catalyst and $t$-BuONa under an oxygen atmosphere afforded bicyclic product 13 in $89 \%$ yield and 3:1 dr. The analogous hydroamination of $\mathbf{1 4}$ afforded bicycle $\mathbf{1 5}$ in $99 \%$ yield and >20:1 dr (Scheme 4, eq 7).

We briefly examined deprotection of the $N$-arylsulphonyl group to afford the corresponding $\mathrm{NH}$ guanidine product. We have previously illustrated that $N$-tosyl groups can be cleaved 
from 2-aminoimidazoles (aromatic guanidine derivatives) via reduction with $\mathrm{Li} / \mathrm{naph}$ thalene. Unfortunately, our preliminary efforts to apply those conditions to the cyclic guanidine $\mathbf{5 b}$ gave unsatisfactory results. Analysis of the reaction mixture by NMR and ESI-MS indicated the $N$-tosyl group was cleaved, but competing cleavage of the $N$-benzyl group was also observed. In addition, it proved to be very difficult to recover the deprotected material after aqueous workup due to water solubility. However, deprotection of the corresponding $\mathrm{N}-4$ methoxyphenylsulfonyl derivative $\mathbf{7}$ under acidic conditions afforded the desired guanidinium salt 16 in $60 \%$ yield (eq 8 ).

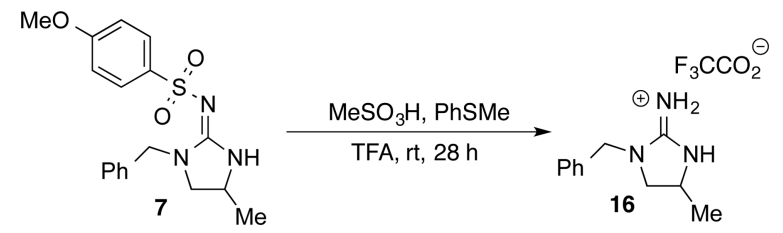

Currently the mechanism of the Ag-catalyzed alkene hydroamination reactions remains unclear. We have no evidence to suggest these transformations do not proceed in a manner analogous to other hydroamination reactions that employ electrophilic late-metal catalysts (alkene activation by the catalyst, attack of the pendant nucleophile, and protodemetallation). However, in contrast to typical late-metal catalyzed alkene hydroamination reactions, which are typically conducted under neutral or slightly acidic conditions, the strong base $t$ - $\mathrm{BuONa}$ is essential for our transformations. Thus, it is possible these reactions proceed via an atypical pathway. The role of oxygen is also not entirely clear at this point. However, the observation that the hydroamination of $\mathbf{3 a}$ in degassed chlorobenzene solvent under a $\mathrm{N}_{2}$ atmosphere proceeded to $60 \%$ conversion (Table 1, entry 16) with $10 \mathrm{~mol} \%$ catalyst and full conversion (99\% yield) with a full equivalent of $\mathrm{AgNO}_{3}$ (Table 1, entry 17) indicates oxygen is not essential for reactivity or catalyst turnover. As such, it appears likely that oxygen plays a role in stabilizing (or preventing reduction of) the silver catalyst.

In conclusion, we have developed the first metal-catalyzed intramolecular alkene hydroamination reactions of guanidine nucleophiles. These transformations provide access to five-membered cyclic guanidines bearing methyl substituents adjacent to a ring nitrogen atom in excellent yield. Future studies will be directed towards expanding the scope of these transformations and developing enantioselective variants.

\section{Supplementary Material}

Refer to Web version on PubMed Central for supplementary material.

\section{Acknowledgments}

The authors thank the NIH (GM 071650) for financial support of this work. MS acknowledges the UM-ICIQ Global Exchange Program for support of summer research studies at the University of Michigan. 


\section{REFERENCES}

1. (a) Berlinck RGS, Romminger S. Nat. Prod. Rep. 2016; 33:456. [PubMed: 26689539] (b) Berlinck RGS, Trindade-Silva AE, Santos MFC. Nat. Prod. Rep. 2012; 29:1382. [PubMed: 22991131]

2. Selig P. Synthesis. 2013; 45:703.

3. For representative examples, see: O'Donovan DH, Rozas I. Tetrahedron Lett. 2012; 53:4532. Kim H-O, Mathew F, Ogbu C. Synlett. 1999:193.

4. Daniel M, Blanchard F, Nocquet-Thibault S, Cariou K, Dodd RH. J. Org. Chem. 2015; 80:10624. [PubMed: 26492553] and references cited therein.

5. For representative examples, see: Nalli SM, Clarkson GJ, Franklin AS, Bellone G, Shipman M. Synlett. 2008:2339. Huber D, Leclerc G, Ehrhardt JD, Andermann G. Tetrahedron Lett. 1987; 28:6453.

6. For a recent review on the synthesis of cyclic guanidines, see: Lemrova B, Soural M. Eur. J. Org. Chem. 2015:1869.

7. For a recent review, see: Zhang W-X, Xu L, Xi Z. Chem Commun. 2015; 51:254.

8. (a) Hövelmann CH, Streuff J, Brelot L, Muñiz K. Chem. Commun. 2008:2334.(b) Zhao B, Du H, Shi Y. Org. Lett. 2008; 10:1087. [PubMed: 18302393] (c) Kim M, Mulcahy JV, Espino CG, Du Bois J. Org. Lett. 2006; 8:1073. [PubMed: 16524271] (d) Büchi G, Rodriguez AD, Yakushijin K. J. Org. Chem. 1989; 54:4494.(e) Butler DCD, Inman GA, Alper H. J. Org. Chem. 2000; 65:5887. [PubMed: 10987917] (f) Mulcahy JV, Du Bois J. J. Am. Chem. Soc. 2008; 130:12630. [PubMed: 18759394]

9. For recent reviews, see: Julian LD. Top. Heterocycl. Chem. 2013; 32:109. Huang L, Arndt M, Gooßen K, Heydt H, Gooßen LJ. Chem. Rev. 2015; 115:2596. [PubMed: 25721762] Schafer LL, Yim JCH, Yonson N. De Meijere A, Brase S, Oestreich M. Metal-Catalyzed Cross Coupling Reactions and More. 2014GermanyWiley VCH - Weinheim:1135. Müller TE, Hultzsch KC, Yus M, Foubelo F, Tada M. Chem. Rev. 2008; 108:3795. [PubMed: 18729420] Liu C, Bender CF, Han X, Widenhoefer RA. Chem. Commun. 2007:3607.

10. (a) Giles RL, Sullivan JD, Steiner AM, Looper RE. Angew. Chem. Int. Ed. 2009; 48:3116.(b) Gainer MJ, Newbold NR, Takahashi Y, Looper RE. Angew. Chem. Int. Ed. 2011; 50:684.(c) Gibbons JB, Gligorich KM, Welm BE, Looper RE. Org. Lett. 2012; 14:4734. [PubMed: 22966873] (d) Perl NR, Ide ND, Prajapati S, Perfect HH, Duron SG, Gin DY. J. Am. Chem. Soc. 2010; 132:1802. [PubMed: 20095555] (e) Ermolat'ev DS, Bariwal JB, Steenackers HPL, DeKeersmaecker SCJ, Van der Eycken EV. Angew. Chem. Int. Ed. 2010; 49:9465.(f) Kwon K-H, Koch CM, Barrows LR, Looper RE. Org. Lett. 2014; 16:6048. [PubMed: 25393831] (g) Gibbons JB, Salvant JM, Vaden RM, Kwon K-H, Welm BE, Looper RE. J. Org. Chem. 2015; 80:10076. [PubMed: 26360634]

11. Zavesky BP, Babij NR, Fritz JA, Wolfe JP. Org. Lett. 2013; 15:5420. [PubMed: 24147839]

12. For related $\mathrm{Pd}$-catalyzed carboamination reactions between $N$-propargyl guanidines and aryl bromides that afford substituted 2-aminoimidazole products, see: Zavesky BP, Babij NR, Wolfe JP. Org. Lett. 2014; 16:4952. [PubMed: 25198672]

13. For reviews on Pd-catalyzed alkene carboamination reactions, see: Wolfe JP. Top. Heterocycl. Chem. 2013; 32:1. Shultz DM, Wolfe JP. Synthesis. 2012; 44:351. [PubMed: 23243321] Wolfe JP. Synlett. 2008:2913. Wolfe JP. Eur. J. Org. Chem. 2007:517.

14. (a) Fornwald RM, Fritz JA, Wolfe JP. Chem. Eur. J. 2014; 20:8782. [PubMed: 24938206] (b) Peterson LJ, Wolfe JP. Adv. Synth. Catal. 2015; 357:2339. [PubMed: 26622222]

15. For reviews on Ag-catalyzed syntheses of heterocycles, see: Alvarez-Corral M, Munoz-Dorado M, Rodriguez-Garcia I. Chem. Rev. 2008; 108:3174. [PubMed: 18630971] Weibel J-M, Blanc A, Pale P. Chem. Rev. 2008; 108:3149. [PubMed: 18616324] 
<smiles>PN[Hg]Cl</smiles><smiles></smiles>

4-bromotoluene

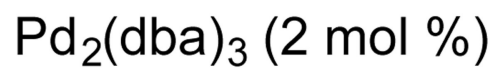

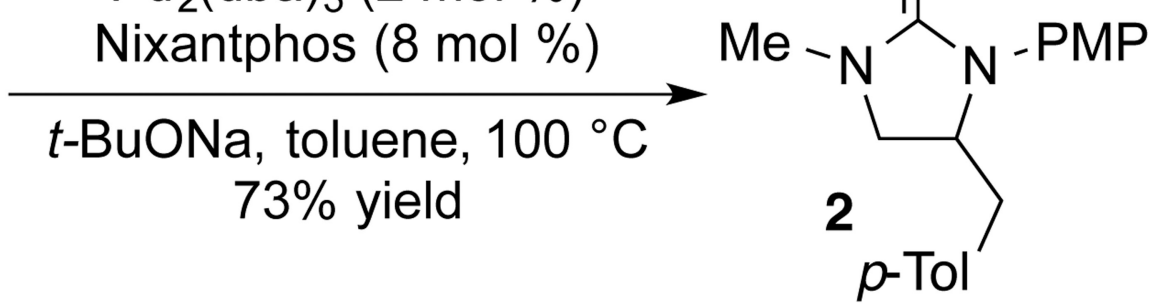

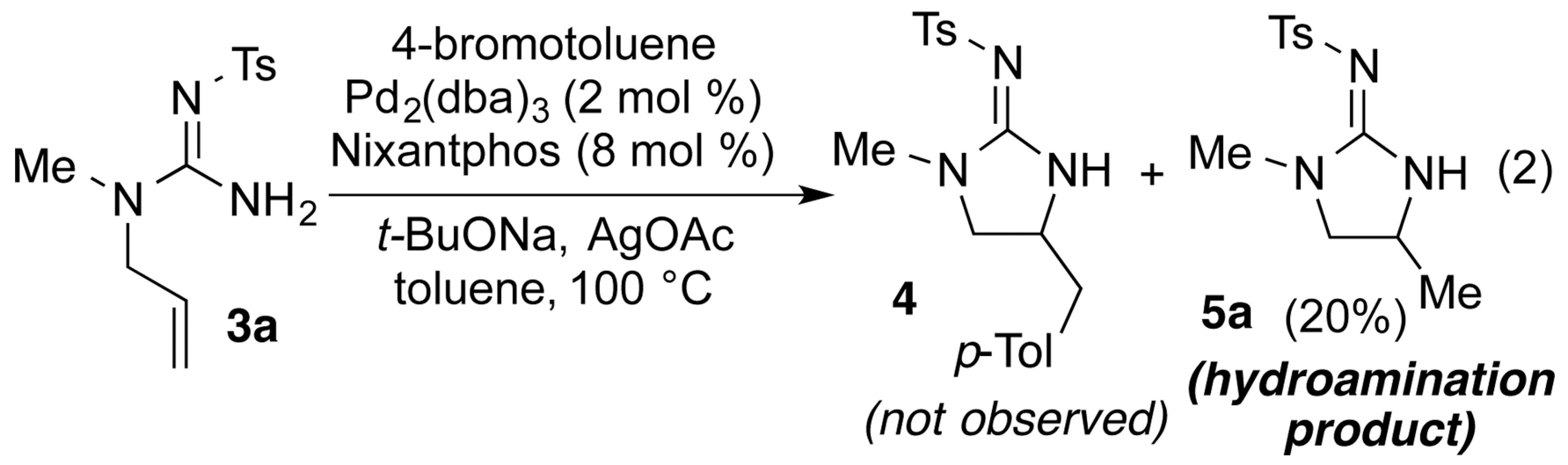

Scheme 1. 
$\mathrm{MeO}$<smiles>C=CCN(Cc1ccccc1)/C(N)=N\S(=O)(=O)c1ccc(O)cc1</smiles>

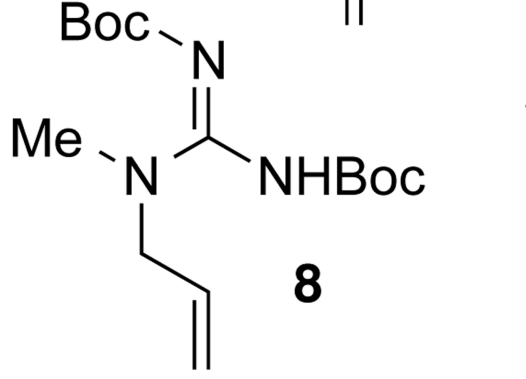

$\mathrm{AgNO}_{3}(15 \mathrm{~mol} \%)$

$t$-BuONa, chlorobenzene

NR

Scheme 2. 
<smiles>[R7]C([R7])=C/C=N\C(N)=N/[As]</smiles>

9, $\mathrm{R}^{1}=$ cyclopropyl, $\mathrm{R}^{2}=\mathrm{H}, \mathrm{n}=1$

10, $R^{1}=H, R^{2}=M e, n=1$

11, $R^{1}, R^{2}=H, n=2$

Scheme 3.

$\mathrm{O}_{2}, 100^{\circ} \mathrm{C}$ 
<smiles>C=CC1CCCCN1C(N)=N[As]</smiles>

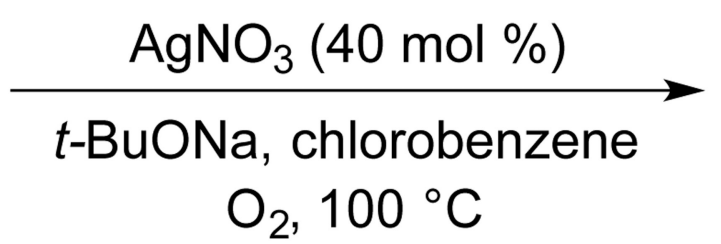
$89 \%, 3: 1 d r$<smiles>C[C@H]1NC(=N[As-])N2CCCC[C@H]12</smiles><smiles>C=C1CCCCC1N(Cc1ccccc1)/C(N)=N/F</smiles>
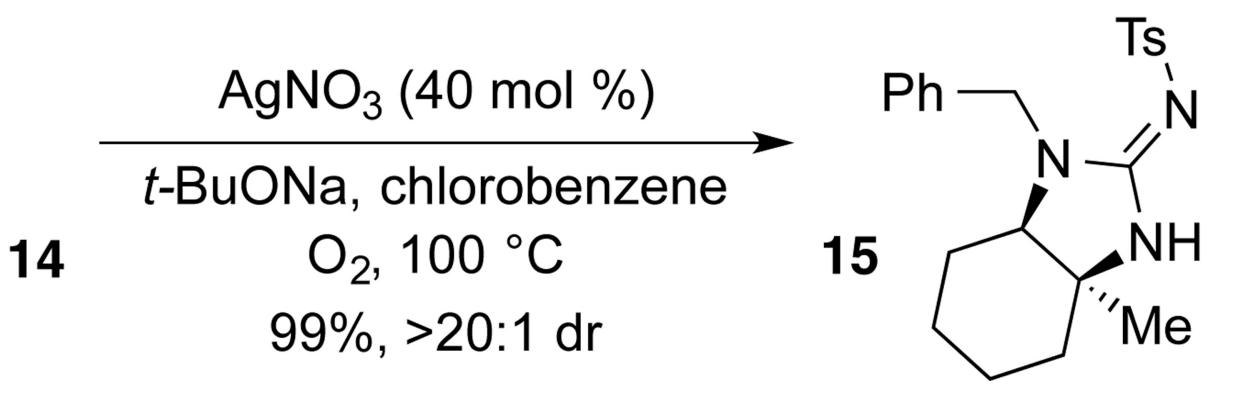

Scheme 4. 

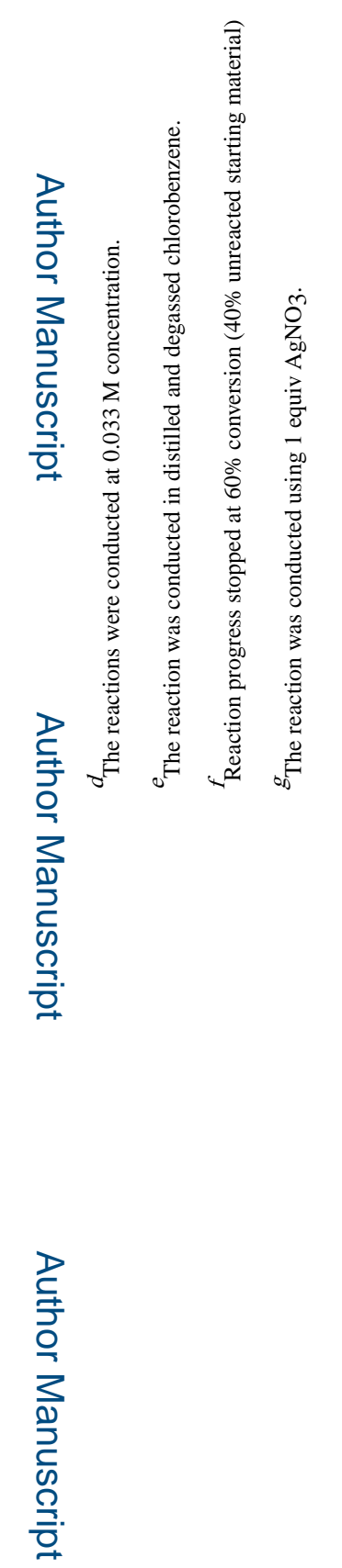

로을

Org Lett. Author manuscript; available in PMC 2017 May 20. 


\section{롤 \\ }

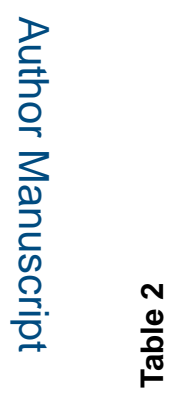

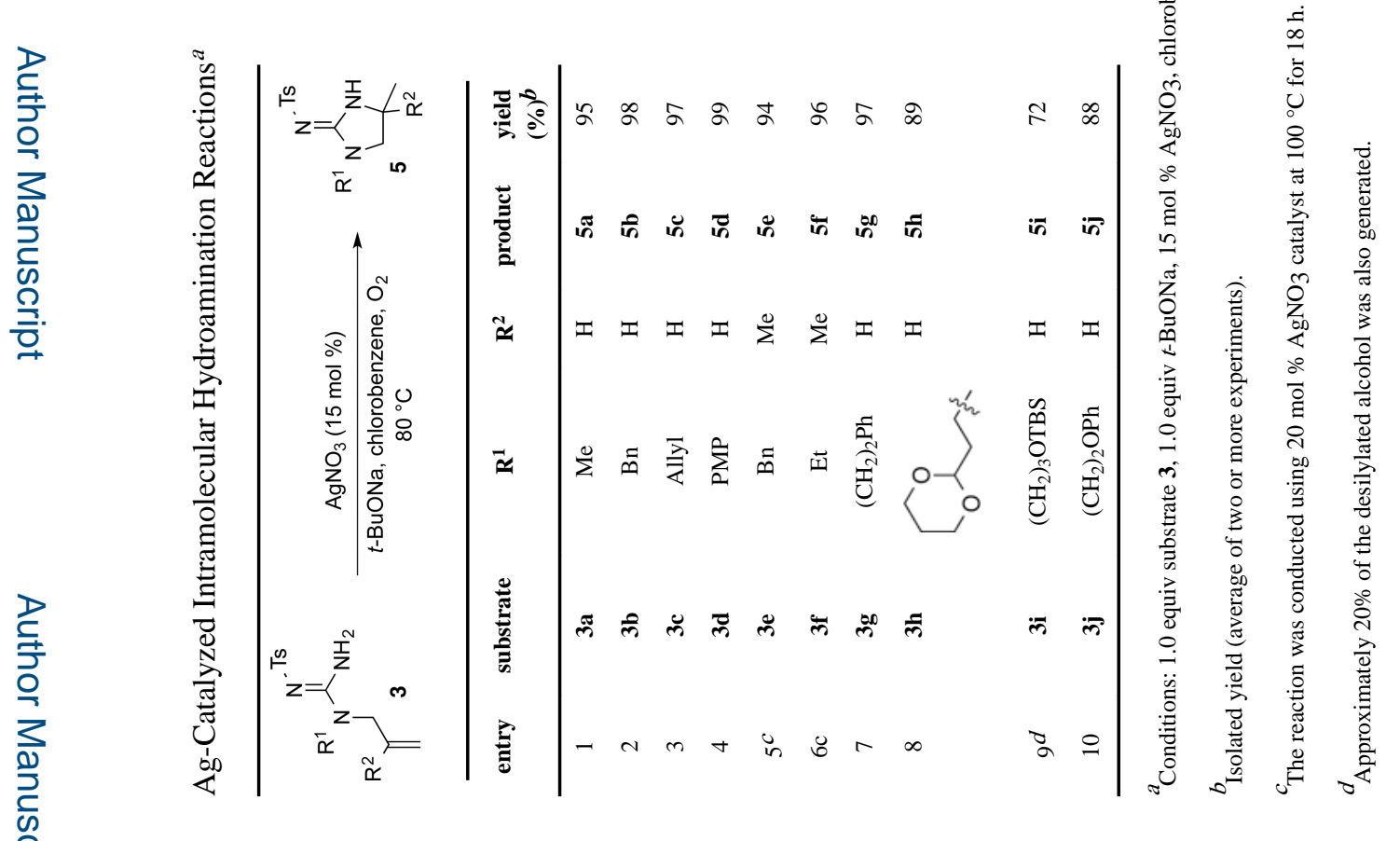

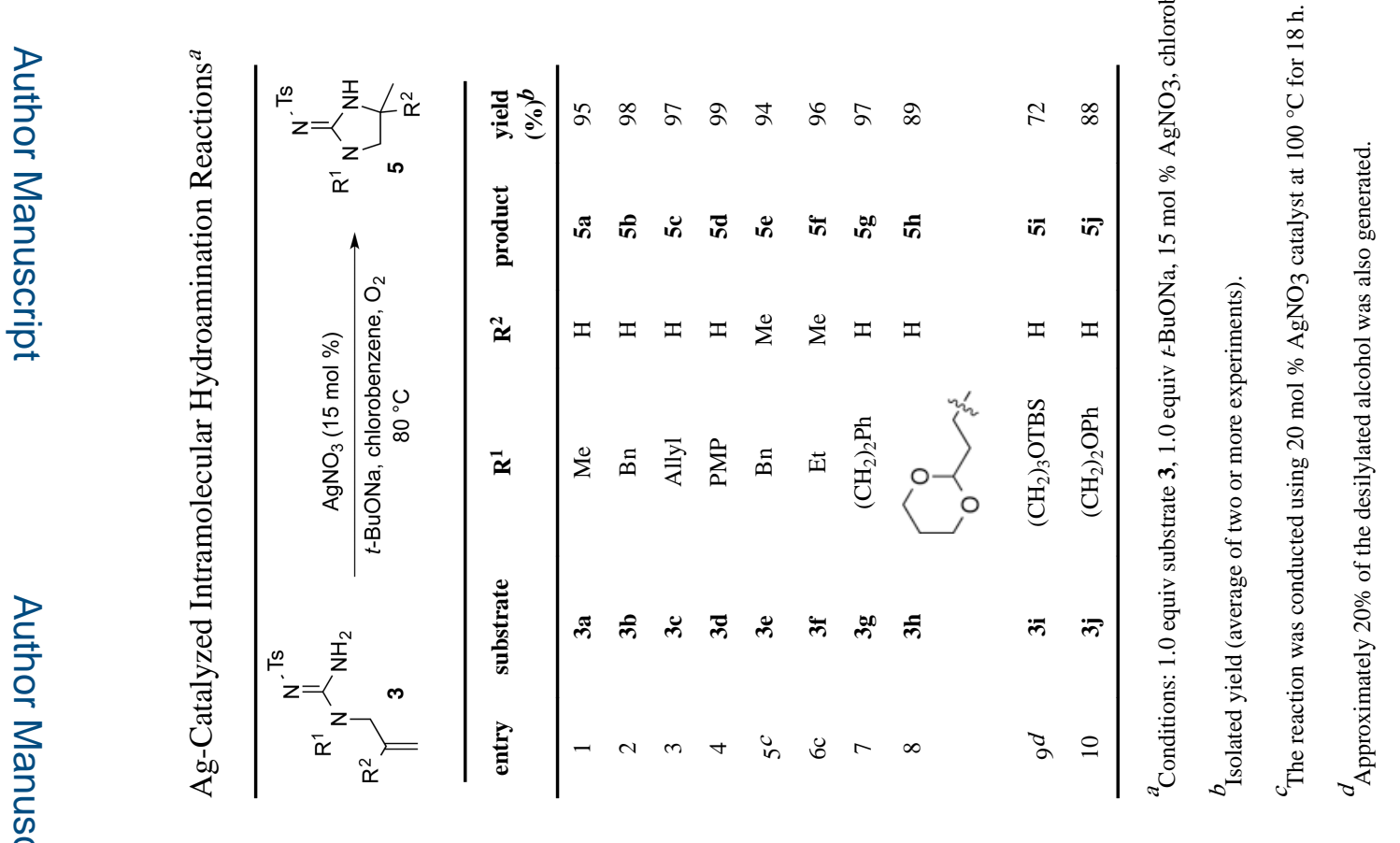

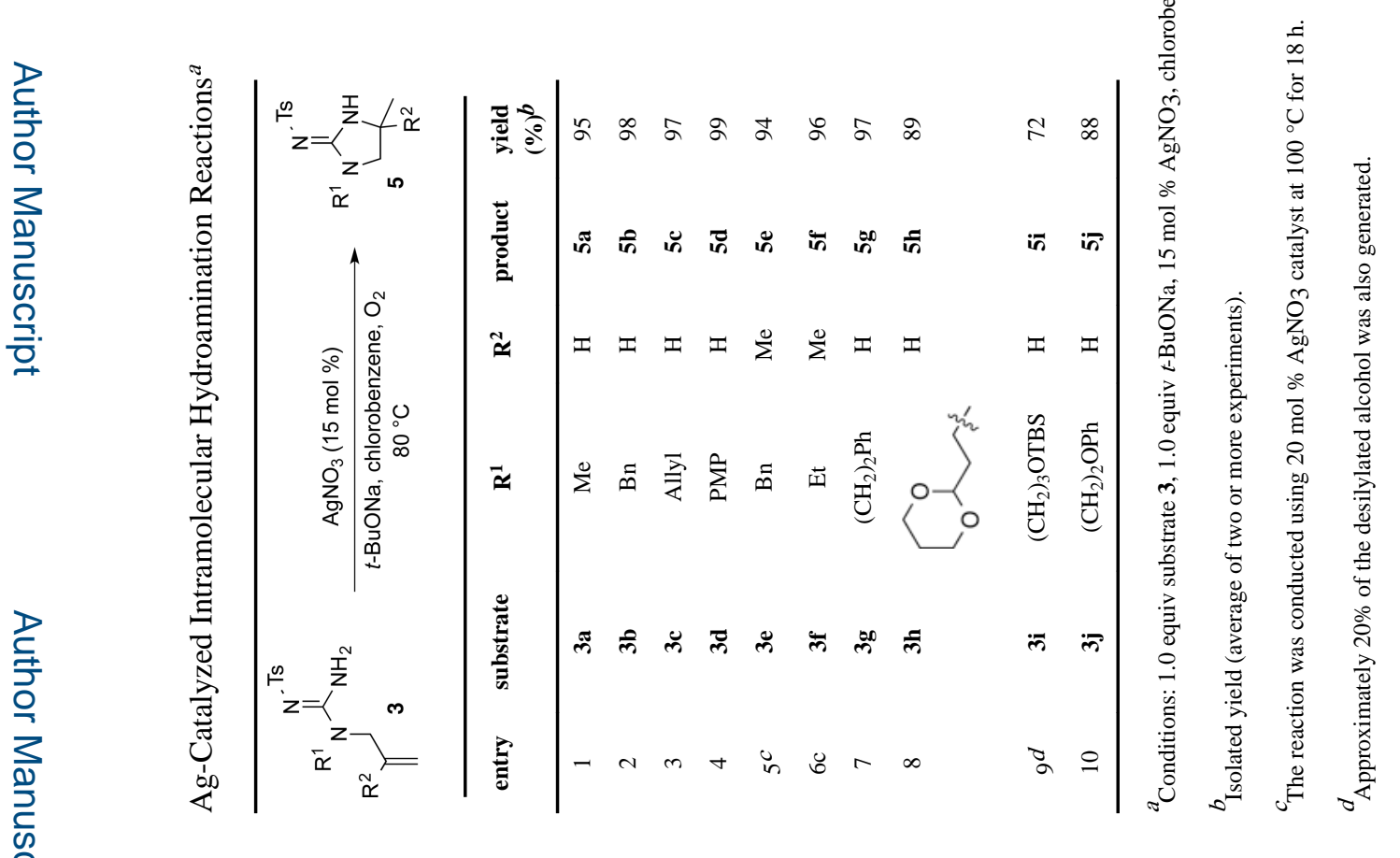

Org Lett. Author manuscript; available in PMC 2017 May 20. 